\title{
Geomechanical Estimation of Unique Deposits of Soft Iron Ores Under High Pressure Aquifers
}

\author{
Vladimir Leonidovich Trushko and Anatoliy Grigoryevich Protosenya
}

The National Mineral Resources University (The Mining University), Russia, 199106, Saint Petersburg, 21-st Line V.O., 2.

DOI: http://dx.doi.org/10.13005/bbra/1974

(Received: 30 September 2015; accepted: 06 November 2015)

\begin{abstract}
This paper deals with the hydrogeological specifics of developing the unique Yakovlevo deposit of rich iron ores of the Kursk magnetic anomaly (Russia) with discovered reserves of 9.6 billion $\mathrm{mt}$ and iron content up to $69 \%$. The analysis of the methods of the development of mineral wealth deposits with high pressure aquifers in the covering rock mass was done, and rational approaches and criteria were found to ensure safe mining. The methodology was developed, and modeling of rock mass shift was made for basic stages of deposit's development taking into account the construction of protective cover. Shift arch size and rock mass shift distance during excavation and stowing were found. The concept of rational development of ore chute was offered taking into account mining safety and economic feasibility of development. On the basis of the dependencies of rock ore mass and enclosing rocks deformation found during ore chute development, basic parameters of protective cover and excavation procedure were reasoned.
\end{abstract}

Key words: Underground working, iron ore, aquifers, hydrogeomechanical model, rock mass shift, rational parameters.

The Yakovlevo iron ore deposit of Kursk magnetic anomaly is unique by the reserves and iron content in ore (up to 69\%), as well as by the complexity of mining geological and hydrogeological conditions, also characterized by flooding. Deposit's ground waters are developed in sedimentary cover's deposits consisting of seven aquifers (from top to bottom): Maastrichtturonian, cenomanian-albian, apt-neocomian, Volga, callovian-bathonian, lower carboniferous (lower carbon), ore crystalline limited to precambrian deposits of rich iron ores and enclosing rocks - banded iron formations, shale

\footnotetext{
* To whom all correspondence should be addressed.
}

rocks, granites, etc. The total flooded area's depth exceeds $700 \mathrm{~m}$. All aquifers are high pressure ${ }^{1}$.

Directly above the ore body there is high pressure lower carboniferous (lower carbon) aquifer with pressure at $420-440 \mathrm{~m}$, limited to limestones, which lower part of profile contains non-persistent clay bands.

Rock ore mass is represented by a thick layer of interstratified ore varieties with bands of iron micaceous martite, finely banded iron micaceous formations and gangue quartz from a few centimeters to a few meters thick. Ore body's dip angles are $65-75^{\circ}$, thickness is $240-280 \mathrm{~m}$. The rock mass is divided into blocks with a few large geological abnormalities.

The highest iron content is seen in micaceous ores. In martite hydrohematite and 
hydrohematite ores, iron content is lower. The iron content depends on the thickness of ore chute thickness grows causing, as a rule, iron content increase in ore. In the middle area of the Yakovlevo deposit, from 10-20 to 200-250 m thick, up to 69\% of iron is contained (Figure 1). In the footwall on the border with banded iron from 0.5 to $12 \mathrm{~m}$ thick, the iron content drops to $45-52 \%$.

Within the ore crystalline complex of rocks, eight fracture systems were found: four systems of bedding joints and four systems of shear fractures. Bedding joints with interstratal faults will affect the residual water content of workings. If banded quartzite occurs in the footwall, such fracture systems will affect greatly the stability of rock mass. Small fissility (cleavage) caused by banding plications of rocks will not exert any great effect on rock mass's stability ${ }^{2}$. The intensity of bedding joints is caused by rocks schistosity and silicate bands being typical gliding planes.

Shear fractures together with bedding joints form the side structure of the rock mass and greatly affect its stability ${ }^{2-3}$.

The key values of physical and mechanical properties of rocks and ores of the Yakovlevo deposit ${ }^{4}$ are listed in Table 1 . The properties of ores of various mineralogical structure differ greatly. The most porous, hydrophilic and soft are loose claylike varieties of goethite ores, able to bind great amounts of water and respectively maximally reduce their density with extra moisturizing.

Typically, over a mining zone two zones of disturbance are formed, affecting hydraulic conductivity ${ }^{5-8}$ : high fissility zone and water conducting rocks zone. To do mining works under aquifers, water conducting zone is of great interest as it is the source connecting aquifers with mining sites.

In the national coal basins, certain experience has been accumulated in developing coal layers under water bodies. Using the experience of layers development it was found that the height of water-blocking stratum taken as fracture penetration during seam extraction varies ${ }^{9-}$ ${ }^{15}$ within a wide range (12-35 of mineable seam thickness $m$, for Donbass - 40-50 $m$ ).

By modeling on equivalent materials, estimation of fissility development of mined rock mass was done ${ }^{14}$. Filtering capacity of the mined rock mass was assessed by water passage. To do this, colored water was poured above the model, passed through the mined rock mass and got into measuring vessel.

Modeling results to find filtration coefficient $K$, consumption $q$ and speed of water $v$ depending on order of working $H / m$ are on Figure 2 .

From the experimental analysis it follows that in case of waterproof ceiling size (sequence of working) $H / m<20$, sharp increase of water flows and filtration coefficient are observed. Therefore, the height of waterproof stratum $I$ should exceed $20 \mathrm{~m}$.

Meantime, the author [14] states that while finding the waterproof stratum, instead of limit height of zone of fissure spread over excavations but the height of through cracks which enable great water passage into workings; accounting for that factor should decrease waterproof stratum to (12-16) $\mathrm{m}$.

Chinese scientists did a lot of field studies which showed that the height of disturbed rocks stratum depends on their lithology and strength and the formation dip. Upon the results of field studies [5,7], the formulae were obtained to find the maximal height of disturbed rocks and caved area $^{1-4}$ :

For high strength rocks (UCS > $40 \mathrm{MPa}$ ):

$$
H_{f}=\frac{100 \cdot m}{1.2 \cdot m+2}
$$

where: $H_{f}$ - maximal height of rocks disturbance; $m$ - mined seam thickness, m; UCS - uniaxial compression strength of rocks.

For middle strength rocks (UCS > 20 - 40 MPa):

$$
H_{f}=\frac{100 \cdot m}{1.6 \cdot m+3.6}+5.6
$$

For low strength rocks (UCS $<20 \mathrm{MPa}$ ):

$$
H_{f}=\frac{100 \cdot m}{3.1 \cdot m+5}+4
$$

For weathered low strength rocks:

$$
H_{f}=\frac{100 \cdot m}{5 \cdot m+8}+3
$$

Calculations using the above formula show that the height of disturbed rocks zone at 
$m-4 m$ is $26.9 m$ and $17.3 \mathrm{~m}$.

The analysis of the official data on North China's mines shows that about 285 out of 600 core coal mines with coal reserves over 25 billion $\mathrm{mt}$ are under the threat of flooding or water invasion at mining stage. Disturbances in waterproof stratum may be catastrophic and cause mine's full or partial closing ${ }^{5,7}$.

In a general case, there are two methods of solving the problem of developing deposits located under aquifers. First, draining before mining. Second, deposit's development without preliminary draining.

The geological studies and mining practice in severe hydrogeological conditions showed that drainage exerts great negative effect on the ecology ${ }^{16}$. Water pumping in the mining area affects the whole aquifer. Looking at China's practice, drainage was done in provincial deposits Wangfen colliery and Hebei. Water pumping was $96 \mathrm{~m}^{3} / \mathrm{min}$, while water level decrease in the central well was $2.8 \mathrm{~m}$ only and the radius of depression cone was great. Drinking water wells were damaged causing water shortage for over 100,000 people. Therefore, drainage method did not become widespread in deposits development in severe engineering and geological conditions. Thus, the most feasible method is the development without preliminary drainage. So, detailed study of the geological structure and hydraulic mode changes as a result of mining works is important.

\section{Methodology}

Stress redistribution effects while draining rock ore mass were studied based on finite elements models representing ore body as a uniform mass and a mass built of various types of ores with rocks intercalations.

The tasks on stress-strain behavior of homogenous linearly deformed rock mass enclosing workings was solved in flat (bidimensional) plane, gravity-based, rock mass was represented by linearly deformed medium ${ }^{17}$. Finite elements model is a section of rock mass $500 \mathrm{~m}$ wide and $900 \mathrm{~m}$ deep. Geological section of the model is shown on Figure 3, the section complies with III-1800 profile. The values of physical and mechanical parameters of the rocks are listed in Table 2.

The first stage covered finding the dependencies of stress-strain behavior of the rock mass on the mining sequence, geometric sizes of rooms/chambers and interchamber pillar in the first layer under roofing.

Roof thickness was constant for all variants $-3 \mathrm{~m}$.

Variant's optimality criterion was the maximal disturbance inside the general arch of disturbance and the ability to reach low border of carbonic rocks.

The second modeling stage covers finding the dependencies of stress-strain behavior of the rock mass with various thickness of roofing and existing/non-existing embedding of the roofing into footwall rocks. Totally, 7 variants of calculation schemes were considered, modeling stress-strain behavior of the rock mass without roofing, with roofing 1, 2, 3, 4, $6 \mathrm{~m}$ thick with stiff embedding into solid rocks and $3 \mathrm{~m}$ roofing without embedding.

The criteria for choosing rational geometric parameters were the values of vertical and horizontal disturbances.

When comparing two technically possible variants of stratified block mining - upward and downward, the criterion was the protective roofing deposits, lower and upper borders of carbonic rocks. The task was solved on bi-dimensional and volumetric finite elements models.

The volumetric model was used for the control of results at modeling stages. The basic volume of tasks on modeling ore body mining upward and downward was bi-dimensional.

For horizons $-365,-395$ and $-425 \mathrm{~m}$, vertical and horizontal stress values were obtained. Distances between sidewall and footwall of the ore body are divided into equal segments (total 12 segments). The distance between segment ends on horizon $-365 \mathrm{~m}$ is about $20 \mathrm{~m}$, on horizon $395 \mathrm{~m}$ about $18 \mathrm{~m}$, on horizon $-425 \mathrm{~m}$ about $15 \mathrm{~m}$. Different length of segments is explained by the fact that footwall and sidewall have different dip angles.

\section{RESULTS}

The modeling of rock mass disturbance process at main stages of protective roof/cover construction for primary mining area of the Yakovlevo deposit was carried out. The sizes of arch disturbance and rock mass disturbance during room-driving and stowing operations were found. 


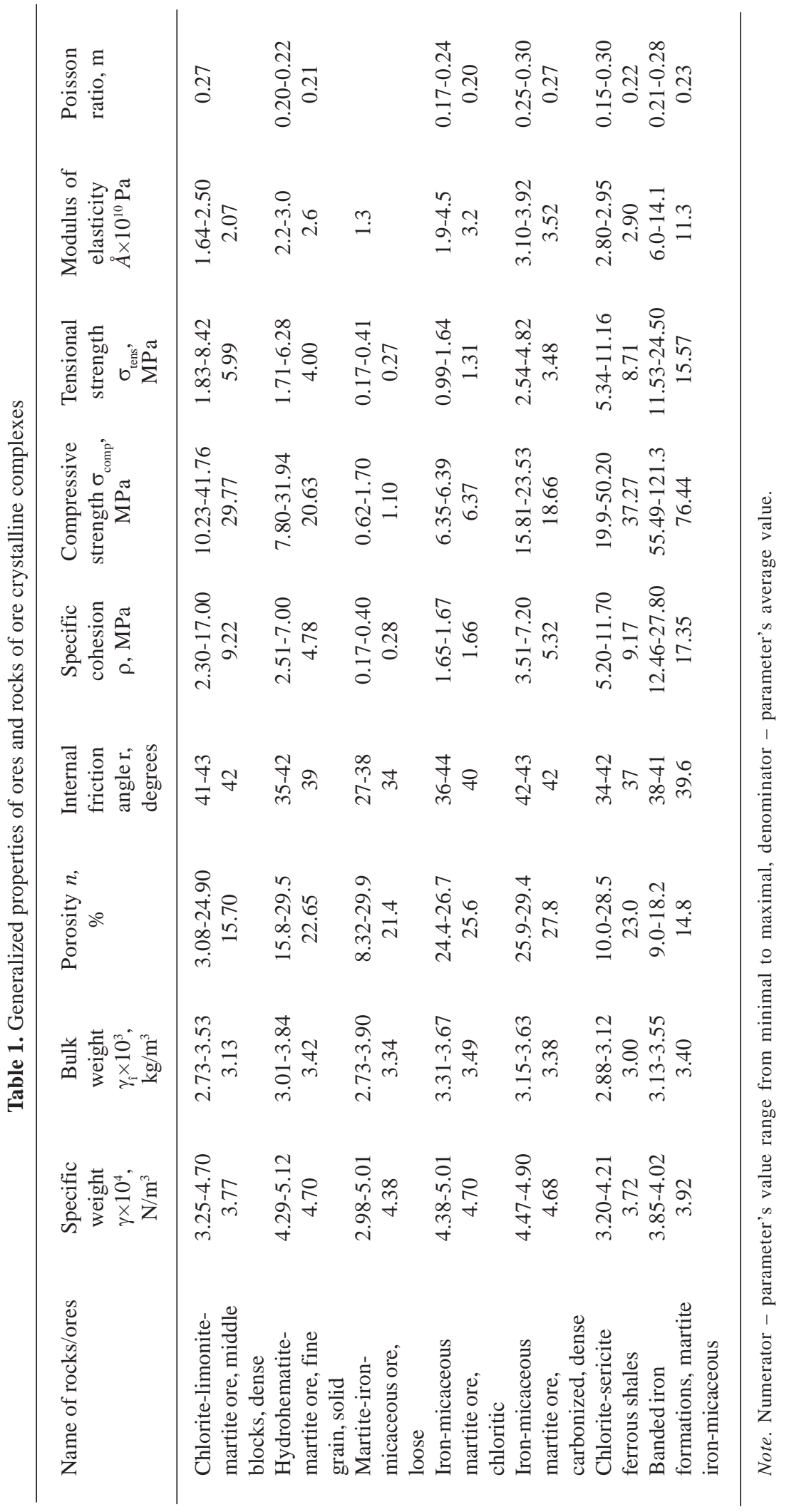


Room-driving via every other pillar, third line room driving via pillar between concrete bands were studied (Table 3).

It was found that mutual location of rooms greatly affects the view of vertical shifts distribution. The most rational, from the rocks strata shift's point of view, is the variant of rooms location closer to the free end of the plate. Meantime, maximal shifts and total roofing size proved minimal.

On Figure 4, numeric values of stress at

Table 2. Physical and mechanical parameters of rocks and soils

\begin{tabular}{llll}
\hline \multirow{2}{*}{ Name of rock/soil } & \multicolumn{3}{c}{ Parameters } \\
\cline { 2 - 4 } & E, MPa & $\mathrm{n}$ & $\mathrm{g}, \mathrm{kN} / \mathrm{m}^{3}$ \\
\hline 1. Tertiary sand-clay deposits & 200 & 0.27 & 19.2 \\
2. Chalk-stone, marl & 6,300 & 0.24 & 27.3 \\
3. Sands, sandstones, clays & 480 & 0.32 & 22.6 \\
4. Clays (bathonic-bajocian) & 460 & 0.34 & 28.2 \\
5. Limestones (carbonic, clayish) & 3,640 & 0.29 & 29.0 \\
6. Re-deposited ores (weak) & 600 & 0.26 & 34.0 \\
7. Aleurolites-phyllites (middle density) & 75,000 & 0.24 & 28.0 \\
8. Loose ores & 500 & 0.26 & 34.4 \\
9. Enclosing quartzites & 55,000 & 0.26 & 29.0 \\
\hline
\end{tabular}

Table 3. Arch disturbance during making protective roof/cover (plate) (downward mining)

\begin{tabular}{llccc}
\hline S. & Stages of work & \multicolumn{3}{c}{ Parameter's name and value } \\
\cline { 3 - 5 } No. & & $\begin{array}{c}\text { Maximal settlement } \\
\text { in arch } \\
\text { disturbance, } \mathrm{m}\end{array}$ & $\begin{array}{c}\text { Settlement of } \\
\text { lower border of } \\
\text { carbon stratum, } \mathrm{m}\end{array}$ & $\begin{array}{c}\text { Settlement of } \\
\text { upper border of } \\
\text { carbon stratum, } \mathrm{m}\end{array}$ \\
\hline 1. & Single room & 0.150 & - & - \\
2. & Primary rooms driving & 0.159 & 0.0318 & 0.0289 \\
3. $\quad$ Secondary rooms driving: & & & 0.0158 \\
& * only from secondary rooms & 0.115 & 0.0493 & 0.0447 \\
4. $\quad$ Thinal, accounting for previous stage & 0.161 & 0.0104 & 0.0093 \\
& * only from third-line rooms & 0.0812 & 0.060 & 0.054 \\
& * final, accounting for previous stage & 0.178 & 0.060 & 0.054 \\
\hline
\end{tabular}

Table 4. Shift arch parameters during downward development of ore body

S. Ore body development stages

No
Name and value of parameter

\begin{tabular}{ccc}
$\begin{array}{c}\text { Maximal } \\
\text { settlement in } \\
\text { shift arch, m }\end{array}$ & $\begin{array}{c}\text { Settlement of } \\
\text { lower border of } \\
\text { carbon, } \mathrm{m}\end{array}$ & $\begin{array}{c}\text { Settlement } \\
\text { of upper border } \\
\text { of carbon, } \mathrm{m}\end{array}$ \\
\hline $0.178 /-$ & 0.060 & 0.054 \\
$0.275 / 0.110$ & 0.101 & 0.092 \\
$0.360 / 0.109$ & 0.146 & 0.0132 \\
$0.452 / 0.107$ & 0.190 & 0.0172 \\
$0.527 / 0.101$ & 0.232 & 0.209
\end{tabular}

Numerator is the final value of parameter considering all preceding stages; denominator is the value for a particular stage. 
Table 5. Maximal vertical shifts at various thickness of cover, $\mathrm{m}$

\begin{tabular}{|c|c|c|c|c|}
\hline \multirow{2}{*}{$\begin{array}{l}\text { Protective cover } \\
\text { thickness, m }\end{array}$} & \multirow{2}{*}{$\begin{array}{c}\text { Protective } \\
\text { cover }\end{array}$} & \multicolumn{3}{|c|}{ Vertical shifts, cm, on the levels of } \\
\hline & & $\begin{array}{c}\text { contact of rich iron ores } \\
\text { with re-deposited ores }\end{array}$ & $\begin{array}{c}\text { contact of carbon } \\
\text { with ore mass }\end{array}$ & $\begin{array}{c}\text { contact of carbon } \\
\text { with clays }\end{array}$ \\
\hline 0 & 12.0 & 2.50 & 2.0 & 1.50 \\
\hline 1 & 7.10 & 2.30 & 1.55 & 1.40 \\
\hline 2 & 5.20 & 2.20 & 1.50 & 1.30 \\
\hline 3 & 4.74 & 2.20 & 1.50 & 1.30 \\
\hline 3without finishing & 4.57 & 2.16 & 1.46 & 1.28 \\
\hline 4 & 4.75 & 2.20 & 1.50 & 1.30 \\
\hline 6 & 4.99 & 1.87 & 1.17 & 1.0 \\
\hline
\end{tabular}

points by horizon are summarized. The general dependency of stress distribution in ore crystalline rock mass is as follows.

Enclosing rocks are the material two sequences harder than loose ores. Deformation modulus of enclosing rocks and inter-ore bands is measured within 50,000-75,000 MPa. Deformation modulus of ores is within 400-1,000 MPa. The balance in unmined rock mass is characterized by concentration of stress in a more solid medium (enclosing rocks) and release from a weak medium (loose ores). Stresses flow into the rocks which may accumulate them more than the adjacent rocks varieties. According to the geological section (Figure 1), the enclosing rocks form a prismatic body filled with ore. Walls and bottom of that body are represented by quartzites and phyllites accumulating, due to increased solidity, the residual stress which ores cannot accumulate due to low strength. The ore in the prismatic body is discharged from stress.

Stress redistribution effect with concentration near the contact with footwall and sidewall rocks is confirmed. Meantime, vertical stress in the homogenous ore field evenly decreases from the footwall to the sidewall reaching the lowest value near the latter.

Estimated stress acknowledges that fact. Stress on the border of ores and enclosing rocks of the footwall varies for different horizons from 14.8 MPa to 18.3 MPa and is determined by the stress concentration in a more solid medium. Going from the footwall, gradual decrease of stress to 2.57 MPa is observed. Suring the transition from the ore body to the enclosing rocks stress increases sharply to $24.5 \mathrm{MPa}$.
The specific features of stress distribution detected should be taken into account in the course of estimation of stability of workings driven in stress-released zones and concentration at contacts of loose rich iron ores with footwall and sidewall rocks, with dirt bands and at the sections of transition from micaceous iron-martite ores to hydrogematite-martite ores.

Rock mass shifts accounting for all the stages of construction of protective cover were as follows: maximal settlement of the ore body in shift arch was $0.178 \mathrm{~m}$; settlement of low border of carbon was $0.06 \mathrm{~m}$; settlement of upper border of carbon was $0.054 \mathrm{~m}$.

By modeling rocks shift using finite elements method during downward mining of ore body's first line it was found that the availability of protective cover greatly reduces rocks shift in workings' roof. Going from the protective cover evidences the dependency of shift growth on each stratum's development (Table 4).

The value of rocks settlement in the arch of shift was $0.527 \mathrm{~m}$, that of the lower border of carbon stratum was $0.232 \mathrm{~m}$ and upper $-0.209 \mathrm{~m}$.

The process of rocks shift formation during upward development of the first line of ore body was modeled. Growth of shift during development of each stratum of the ore body in relation to preceding stratum development was found.

Maximal settlement in the arch of shift upon 12 strata development will be $1.11 \mathrm{~m}$, settlement of the lower border of carbon stratum was $0.45 \mathrm{~m}$, upper $-0.42 \mathrm{~m}$.

In the course of upward development by strata under protective cover, the settlement of 

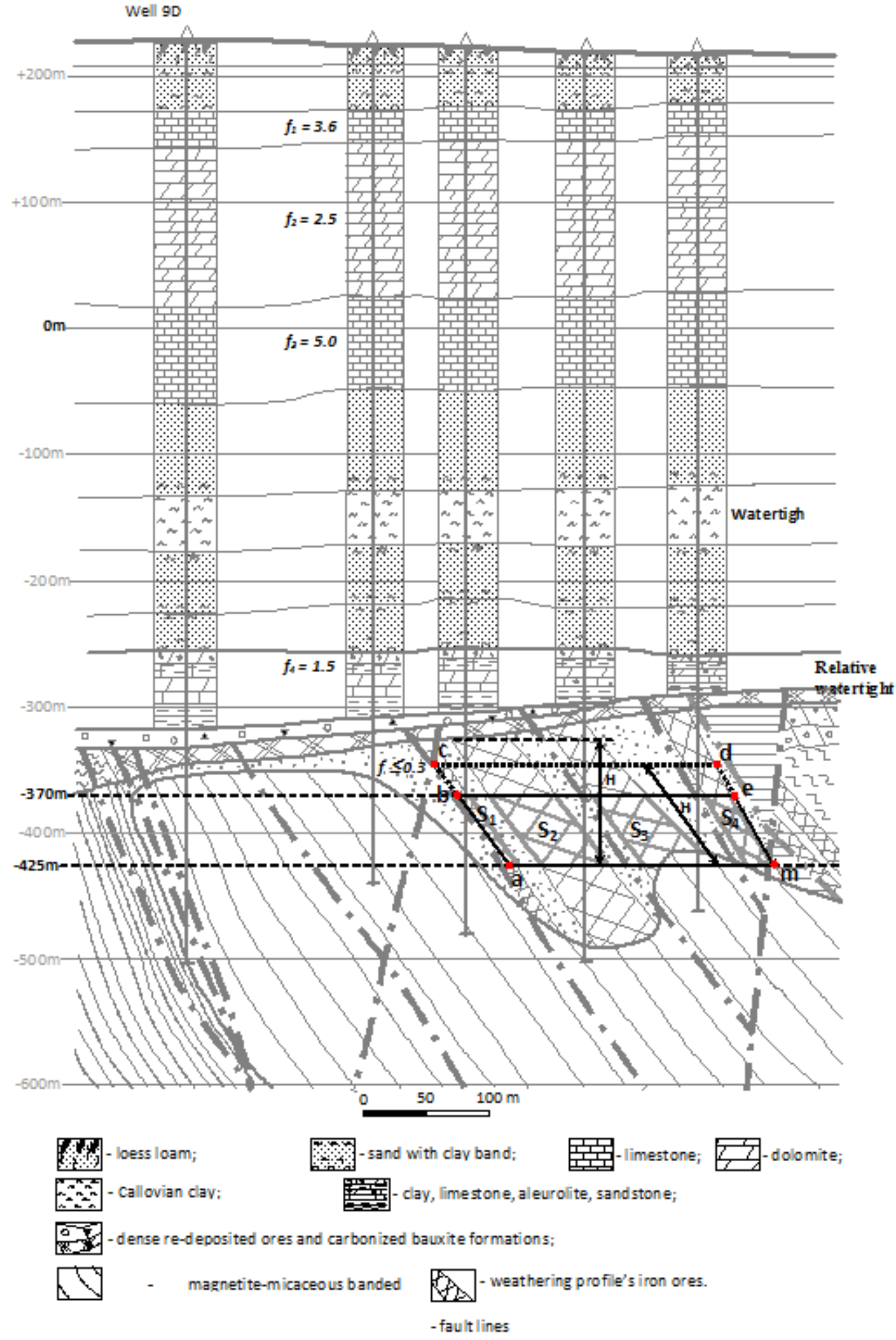

Fig. 1. View along line 29: abem - development contour between aquifer -370m and aquifer -425m; acdm - full development contour; $\mathrm{S}_{1}, \mathrm{~S}_{2}, \mathrm{~S}_{3}, \mathrm{~S}_{4}$ - rich iron ores contour 
cover, lower and upper borders of carbon are twice as high as during downward excavation and backfilling. Besides, large sedimentations of the ore mass (under $1.0 \mathrm{~m}$ ) under the cover create hard conditions for development and support of upper strata's stopes which get into the disturbed ore mass.

The dependency of vertical shifts on the thickness of protective cover may be seen in Table 5 and Fig. 5.

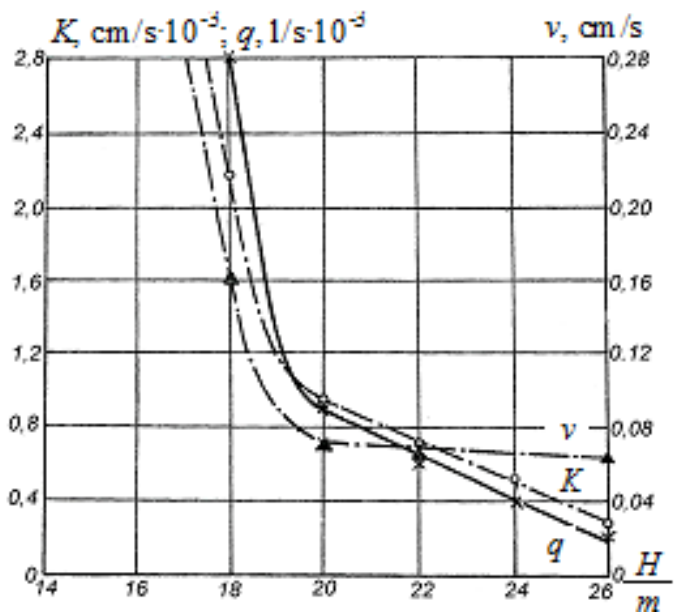

Fig. 2. Dependency of water consumption, filtration coefficient and speed on order of working in the model

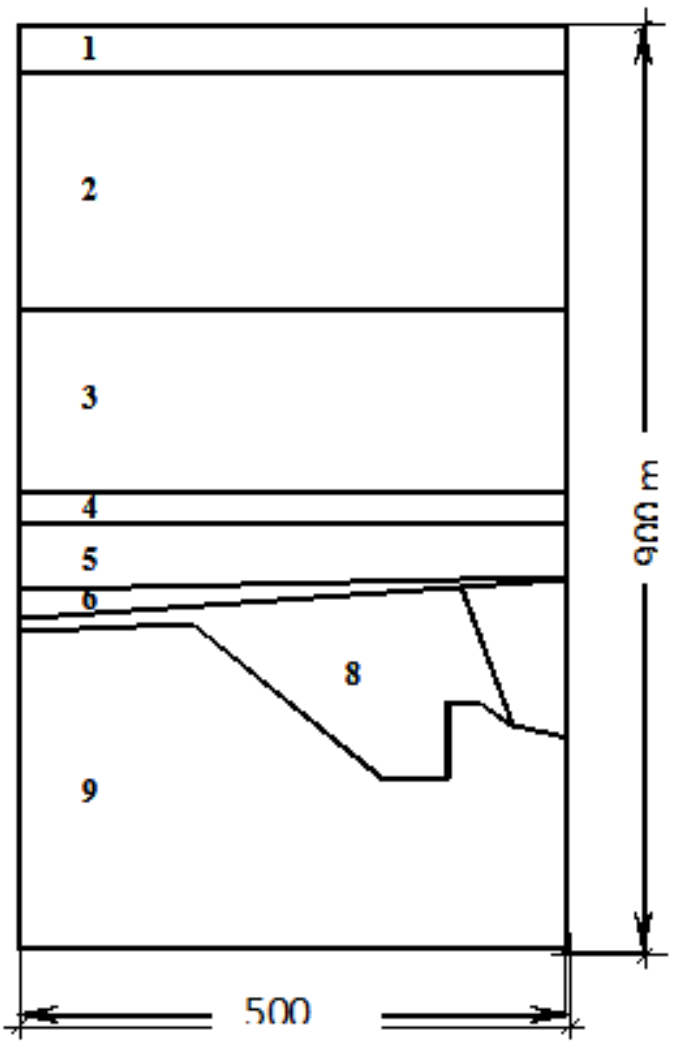

Fig. 3. Scheme of geological profile finite element model 1-9-rocks and soils from Table 1

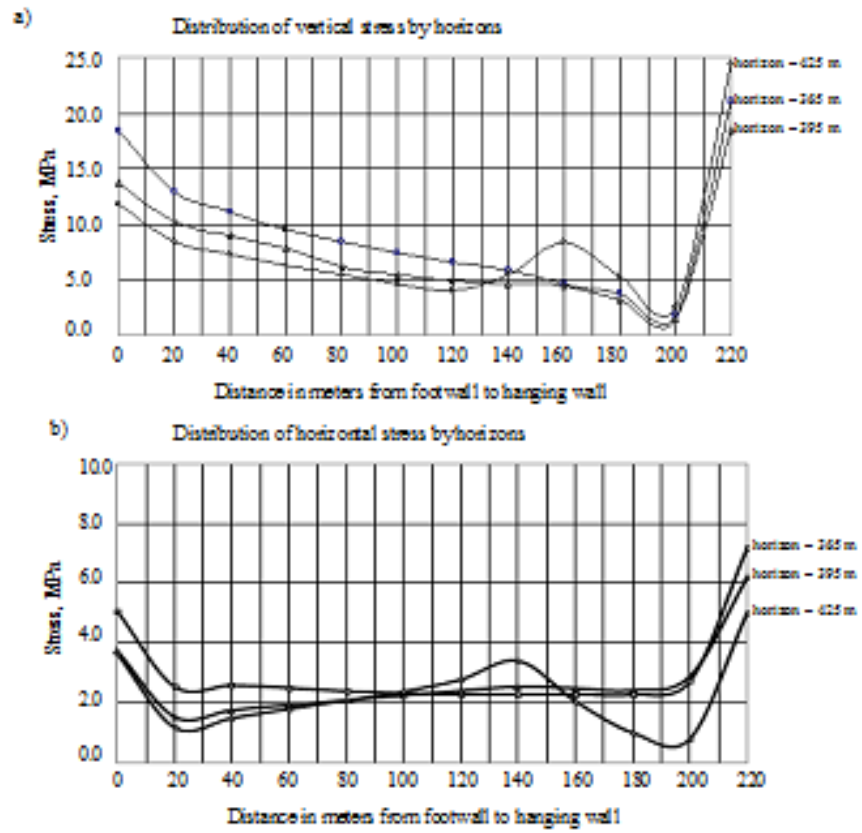

Fig. 4. Stress distribution in the ore body of the Yakovlevo deposit 


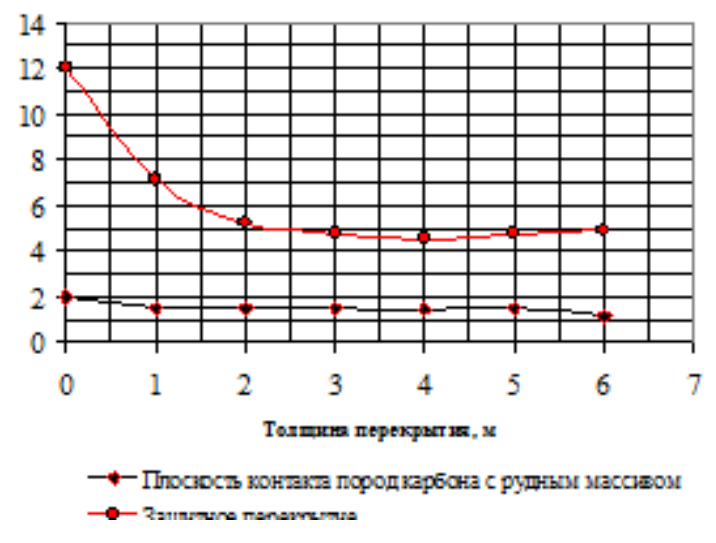

Fig. 5. Dependency of maximal vertical shifts on the thickness of protective cover

As per Table 5, Figure 5 and isochromes of vertical and horizontal shifts it is seen that beginning with the thickness of cover equaling 3 $\mathrm{m}$ that parameter does not exert great influence on vertical shifts in ore strata and cover rocks. Protective cover 3, 4 and $6 \mathrm{~m}$ thick are flexing above the operating area.

The deflection of the cover above the operating area during stoping predetermines the high level of flexion stress. Maximal stress was seen near backfilling: at $3 \mathrm{~m}$ cover thickness 99.4 MPa, 4 m - 88 MPa, 5 m - 86.3 MPa, 6 m 83.4 MPa.

So, increased cover thickness will not be able to affect waterproof stratum shift. Deformations may be minimized only via optimal control over overburden stress ${ }^{18-20}$ - choosing rational sequence of rooms drilling and good quality backfilling.

When rooms are driven in a rock mass, low vertical stress area above the protective cover is formed. It has strict dome shape with the breadth along the protective cover, 5-8 $\mathrm{m}$ exceeding the driven spatial span and the height not exceeding its half.

\section{DISCUSSION}

Specifics of the natural factors complicating the development of the Yakovlevo deposit and affecting the mining safety and choosing the technological scheme of the mine ensured the selection of the concept containing the following basic provisions: the main criterion for the applicability of ore body development is the avoidance of dangerous deformations and destruction of rocks strata located between mine workings and aquifers, reaching which secondary flooding of the rock ore mass is possible during preparatory and excavation works; in rich iron ore occurrence areas, level's reserves should be extracted downwards simultaneously with full backfilling of the excavated space (goaf) with hardening materials with the parameters excluding drainage fractures in the rock mass; at the initial development stage in the first stratum the breadth and height of excavation workings should be minimally permissible by the affecting factors (equipment dimensions, aeration, clearance required as per Safety rules, etc.) with further stageby-stage adjustment of technological scheme's parameters upwards until they reach optimal values, accounting for additional information on the geological structure and behavior specifics of the rock mass obtained in the course of preparatory and excavation works; the technological scheme applied should be easily adjustable both to the changes in mining geological and mining technical conditions of mining works and to the market situation: in a favorable situation, being able to ensure great production capacity increase of the mine, in an unfavorable situation - to work with minimized economic loss.

In the course of that concept's implementation, ore chute should be developed beginning with the areas adjacent to the footwall and containing the richest micaceous iron martite ores.

To avoid dangerous deformations and water from above strata between the horizon for development and lower carbon border, waterproof ceiling at least $65 \mathrm{~m}$ thick and ferroconcrete cover should be made.

During the ore body's first line development, rich ores should be mined without deposit drainage. Further, as mining works go on, water-pressure horizons level may be decreased.

Based on the above research we concluded that at the first line of the Yakovlevo deposit development, upward sequence of development is not acceptable. Disadvantages include periodical (as strata are developed) deformations of the ore mass in connection with incomplete backfilling of the excavated areas, 
compaction of filling mass and excavation works in strata. In such conditions, to solve the matters on ensuring the stability of roof with excavation cuts and their relation with preparatory works is practically impossible due to safety and economic feasibility factors. For rich iron ore areas, with over $55 \%$ of ores having uniaxial compression $1-15 \mathrm{MPa}$ it is recommended to use downward development of levels as the only way.

Construction of protective cover is a responsible stage of ore body development. The purpose of the protective cover is to ensure safe conditions of ore body's development under cover, to avoid installation of supports of workings and rooms of the first level under the cover, to avoid uncontrolled roof fall above the goaf, to reduce settlement of the above ore mass and carbon rocks to the level safe of water fractures formation.

Due to high material intensity and labor intensity of works on protective cover construction, its responsible role in ensuring safe excavation, it is required to reason the protective cover's parameters: thickness, length cross-line, cover structure (embedding into footwall rocks; without embedding; with reinforcement; without reinforcement; hard rigid and wire-rope reinforcement).

The assessment of effect of support's junction methods on its stress and strain behavior showed that cover supporting instead of embedding into rocks decreases stress in the tension area to $52 \mathrm{MPa}$, i.e., twice, while the maximal stress area moves from embedding to the center of dip over the goaf. Modeling expressly states that embedding in footwall rocks causes sharp stress increase in the protective cover.

\section{CONCLUSION}

In the cover, freely resting on the ore mass, stress remains extremely high for both concrete and ferroconcrete. Therefore the task on constructive measures for release of bending stress from the cover is of urgency. An efficient measure in that regard is insertion of hinged members or plasticity elements into the cover. As such, cold seams between some blocks of the protective cover may be used. Otherwise, the system will be released from stress in an uncontrolled way, with fractures in overstressed areas.
Accounting for basic deformation dependencies of the rock mass and cover during excavation, it is preliminarily recommended:

a) Protective cover thickness should be 3.0$3.5 \mathrm{~m}$. Cover to be made by drilling and filling one ore layer;

b) Protective cover to be made resting on the ore mass without embedding into footwall rocks;

c) To release tensile stress from protective cover while it is deformed as excavation operations are moving forward, longitudinal cross-line reinforcement on the ground should be made in the concrete protective cover, and vertical cracks made through the whole thickness of the cover, oriented along the ore body. Cracks and reinforcement will work as plasticity hinges. The distance between hinges should be compliant with the breadth of goaf subject that one cover block exceeds room's breadth at least three times;

d) Optimal sequence of rooms development of the first layer under cover is going from the sidewall.

The dependencies of protective cover thickness change on stress and strain behavior of the enclosing mass and cover enable to specify the information about the role of protective cover during development of rich iron ore deposits. It is evident that man-made protective cover of any thickness during mining works and growing outcroppings is unable to hold the covering rock mass strata. Settlements of the cover and the above ore mass depend on the number of simultaneously driven rooms, resistance of inter-room pillars, strength and quality of filling mass.

Further, it is feasible to assess the effect of parameters of rich iron ores development system on the changes of stress and strain behavior of the ore mass and the rock mass from the position of ensuring stability of preparatory and excavation stopes/workings.

\section{REFERENCES}

1. Sokolov, G.A. and N.A. Bykhover, Geology, Hydrogeology and Iron Ores of the Kursk Magnetic Anomaly. Moscow: Nedra, 1969.

2. Ruppeneit, K.V., Deformation Ability of 
Fissured Rock Masses. Moscow: Nedra, 1975.

3. Zemisev, V.N., Calculations of Rock Masses Deformations. Moscow: Nedra, 1973.

4. Protosenya, A.G. and V.L. Trushko, Prognostication of Workings Stability in Loose Iron Ores of the Yakovlevo deposit. Physical and Technical Issues of Mineral Wealth Development, 2013; 4: 1-13.

5. Peng, S., Investigation of Engineering Disasters Induced by Coal Mining at Deep Depth in China. In 4th Ann Meeting, Geology Branch, China Coal Industry Tech Committee, Qingdao. (In Chinese), 1997.

6. Peng S., The State-of-Art and the Future Work of Engineering Disasters Induced by Coal Mining at Deep Depth in China. In Symposium on Engineering and Disaster, Dept Material Science and Engineering, China NSF, Mt Jiuhua, Jianxi. (In Chinese), 1999.

7. Zhang, J. and B. Shen, Coal Mining under Aquifers in China: A Case Study. Int. J. Rock Mech. Min. Sci., 2004; 4(41): 629-639.

8. Liu, T., Coal Mine Ground Movement and Strata Failure. Beijing: Coal Industry Publ. House. (In Chinese), 1981.

9. Avershin, S.G., Mining Works under Structures and Water Bodies. Moscow: Ugletekhizdat, 1954.

10. Gusev, V.N., Geomechanics of TechnologyGenerated Water Fractures. Saint Petersburg: SpSMI(TU), 1999.

11. Alborov, Z.B., Development of Foreign
Deposits Located under Water Bodies and Rivers. Moscow: Central R\&D Institute of Information and Technical/Economic Research of Ferrous Metallurgy, 1965.

12. Gvirtsman, B.Ya. et al, Safe Coal Extraction under Water Objects. Moscow: Nedra, 1977.

13. Khokhlov, I.V., Safe Mineral Wealth Mining under Water Bodies. Moscow: Nedra, 1971.

14. Niskovskiy, Yu.N., Finding Safe Depth of Deposits Development under Water Bodies Using Hydrocontrol Method in Equivalent Materials Models. Proceedings of the Mining Institute, 1962; 44: 153-159.

15. Niskovskiy, Yu.N., V.D. Kulnev and N.A. Alekseyev, Practice in Developing Coal Seams under Water Bodies. Coal, 1976; 5: 23-26.

16. Trushko, V.L., A.G. Protosenya and R.E. Dashko, Geomechanical and Hydrogeological Issues of the Yakovlevo Deposit Development. Proceedings of the Mining Institute, 2010; 185: 9-18.

17. Morozov, Ye.M. and G.P. Nikishkov, Finite Elements Method in Mechanics of Destruction. Moscow: Nauka, 1980.

18. Borisov, A.A., Mechanics of Rocks and Rock Masses. Moscow: Nedra, 1980.

19. Turchaninov, I.A., M.A. Iofis and E.V. Kasparyan, Basics of Rocks Mechanics. Leningrad: Nedra, 1977.

20. Bronnikov, D.M. and M.N. Tsygalov, Stowing Operations in Mines. Guide. Moscow: Nedra, 1989. 